\title{
Bacteroides dorei
}

National Cancer Institute

\section{Source}

National Cancer Institute. Bacteroides dorei. NCI Thesaurus. Code C111133.

A species of anaerobic, gram-negative, rod shaped bacteria assigned to the phylum

Bacteroidetes. This specis is non-spore forming, non-motile, does not hydrolyze esculin, is indole negative and nitrate is not reduced. 